\title{
P67L: a cystic fibrosis allele with mild effects found at high frequency in the Scottish population
}

Annette Gilfillan, Jon P Warner, Jean M Kirk, Tom Marshall, Andrew Greening, Ling-Pei Ho, Tim Hargreave, Bryan Stack, Duncan McIntyre, Rosemary Davidson, John C S Dean, Wilson Middleton, David J H Brock

Human Genetics Unit, Molecular Medicine Centre, University of Edinburgh, Western General Hospital, Edinburgh EH4 2XU, UK

A Gilfillan

J P Warner

D J H Brock

Royal Hospital for Sick Children, Edinburgh

EH9 1LF, UK

J M Kirk

T Marshall

Western General

Hospital, Edinburgh

EH4 2XU, UK

A Greening

L-P Ho

T Hargreave

Gartnavel General Hospital, Glasgow G12 OYN, UK

B Stack

Victoria Infirmary, Glasgow G42 9TY, UK D McIntyre

Duncan Guthrie Institute of Medical Genetics, Yorkhill, Glasgow G3 8SJ, UK $R$ Davidson

Department of Medical Genetics, Aberdeen Royal Hospitals NHS Trust, Aberdeen AB25 2ZD, UK

J C S Dean

Medical Unit, St John's Hospital, Livingstone EH54 6PP, UK

W Middleton

Correspondence to: Professor Brock.

Received 7 May 1997 Revised version accepted for publication 4 September 1997

\begin{abstract}
Only three mutant cystic fibrosis (CF) alleles have to date been established as conferring a dominant mild effect on affected subjects who are compound heterozygotes. We now add a fourth, P67L, which occurs on about $1.4 \%$ of Scottish CF chromosomes. Among 13 patients (12 unrelated) with this allele, the average age at diagnosis was $22.5 \pm 11.3$ years. None of the cases had consistently raised sweat chloride concentrations, the average value being $57 \pm 9 \mathrm{mmol} / 1 ; 77 \%$ of the patients were pancreatic sufficient. When compared to three other established mild CF alleles, R117H, A455E, and $3849+10 \mathrm{~kb}$ $C-T$, a compound heterozygote for P67L has minimal disease and clinical suspicions are unlikely to be confirmed other than by DNA typing.

(F Med Genet 1998;35:122-125)
\end{abstract}

Keywords: cystic fibrosis; dominant effect; P67L

Since the cloning of the cystic fibrosis (CF) gene in 1989, a small number of mutant alleles have been found which can be described as having a "dominant mild" effect; the phenotypic effect is mild whatever the nature of the mutant allele on the other chromosome. In a majority of cases these alleles have been so rare that only one or two affected cases have been identified. Kerem and Kerem ${ }^{1}$ suggested that before a genotype-phenotype correlation could be regarded as established, there should be at least 10 unrelated cases of CF patients bearing that allele. On this basis the only accepted mild $\mathrm{CF}$ alleles would be $\mathrm{R} 117 \mathrm{H},{ }^{2} \mathrm{~A} 455 \mathrm{E},{ }^{3}$ and $3849+10 \mathrm{~kb}$ C-T. ${ }^{45}$ The criteria used by Kerem and $\mathrm{Kerem}^{1}$ to define a mild CF phenotype were: diagnosis at a later age, older at the time of the study, lower sweat chloride levels (some with normal or borderline values), better nutritional status, and (usually) pancreatic sufficiency.

The mutation P67L was first described by Hamosh et al. ${ }^{6}$ In the course of a survey of Scottish CF patients we discovered that it occurred more frequently than had been expected. Furthermore, the presentation was in almost all cases atypical. In this report we summarise our experience with $13 \mathrm{CF}$ patients (12 unrelated) who are compound heterozygotes for P67L and other mutant alleles and review the evidence for a dominant mild phenotype.

\section{Materials and methods}

PATIENTS

Patients DO and AL were referred as part of investigation into their infertility. In neither case had cystic fibrosis been suspected until quite late in life. At the ages of 36 and 34, respectively, $\mathrm{DO}$ and $\mathrm{AL}$ were found to have bilateral absence of the vas deferens. However, DO had attended the ENT Department for sinus problems and had had nasal polyps removed when in his teens.

EM presented at hospital aged 9 with cough and breathlessness. Sweat tests were equivocal and he was diagnosed as having asthma. $\mathrm{He}$ had a number of chest infections with wheeze over the next few years. At 15, he was thought to have pulmonary aspergillosis. At 30, finger clubbing was seen and a chest $x$ ray suggested bronchiectasis. Sputum culture grew Haemophilus influenzae, Staphylococcus aureus, and Pseudomonas aeruginosa. At 32, he developed mild malabsorption and was then investigated for CF.

AM was diagnosed as having ulcerative colitis after 8 to 9 years of persistent diarrhoea. At the age of 27, the response of her diarrhoea to pancreatic supplements, a borderline sweat test, productive cough and streaky shadowing on chest $x$ ray, and culture of Staphylococcus aureus and Haemophilus influenzae in sputum led to a clinical diagnosis of CF. However, as both her children had persistent respiratory symptoms, it was later suspected that both AM and her partner might instead be heterozygotes. This was not resolved until the molecular diagnosis.

In childhood, ED had symptoms suggestive of irritable bowel syndrome. Ciliary studies identified abnormally short cilia with a disorganised and focally asynchronous beat. Later she had recurrent chest infections and at the age of 32 chest $x$ ray showed evidence of bronchiectasis, while sputum cultures showed Staphylococcus aureus, Pseudomonas aeruginosa, and Haemophilus influenzae. She is currently pregnant.

The diagnosis in JM had been made at the age of 19 on the basis of a persisting productive cough, occasional haemoptysis, and breathlessness. There was also apparently a positive sweat test, though the date and the records have been lost.

MA was referred to the adult $\mathrm{CF}$ clinic at the age of 21 with an unconfirmed diagnosis of CF. Although reported as having recurrent chest illnesses as a child, he has at present few signs 
Table 1 Characteristics of P67L patients

\begin{tabular}{|c|c|c|c|c|c|c|}
\hline Patient & Sex & $\begin{array}{l}\text { Age at } \\
3 / 97\end{array}$ & $\begin{array}{l}\text { Age at diagnosis of } \\
C F\end{array}$ & Original primary diagnosis & Genotype P67L/ & $\begin{array}{l}\text { Pancreatic } \\
\text { status }\end{array}$ \\
\hline DO & $\mathbf{M}$ & 39 & 38 & Male infertility & $\Delta \mathrm{F} 508$ & PS \\
\hline EM & $\mathbf{M}$ & 35 & 33 & Asthma & $\Delta \mathrm{F} 508$ & PS \\
\hline $\mathrm{AL}$ & $\mathbf{M}$ & 34 & 34 & Male infertility & $\Delta \mathrm{F} 508$ & PS \\
\hline $\mathrm{AM}$ & $\mathrm{F}$ & 34 & 32 & Ulcerative colitis & $\Delta \mathrm{F} 508$ & PI \\
\hline ED & $\mathrm{F}$ & 33 & 33 & Primary ciliary dyskinesis & $\Delta \mathrm{F} 508$ & PS \\
\hline $\mathrm{JM}$ & $M$ & 30 & 19 & Persistent cough, possible CF & $\Delta \mathrm{F} 508$ & PS \\
\hline MA & $\mathbf{M}$ & 27 & 27 & Probable CF & $\Delta \mathrm{F} 508$ & PI \\
\hline LB & $\mathbf{F}$ & 21 & 19 & Asthma & $1717-1 \mathrm{G}-\mathrm{A}$ & PS \\
\hline $\mathrm{JC}$ & $\mathrm{M}$ & 20 & 18 & Recurrent chest infections & G542X & PI \\
\hline $\mathrm{KB}$ & $\mathrm{F}$ & 19 & 16 & Respiratory disease & $\Delta \mathrm{F} 508$ & PS \\
\hline $\mathrm{BH}$ & $\mathbf{F}$ & 15 & 13 & Asthma & $\mathrm{Q} 1291 \mathrm{H}$ & PS \\
\hline SH & $\mathbf{M}$ & 12 & 9 & Possible CF & Q1291H & PS \\
\hline AT & $\mathrm{F}$ & 1 & 1 & Probable CF & $\Delta \mathrm{F} 508$ & PS \\
\hline
\end{tabular}

^PI, pancreatic insufficient; PS, pancreatic sufficient.

of the disorder and has never been admitted to hospital.

LB's presentation was suggestive of asthma but she had poor initial response to bronchodilator therapy and inhaled steroids. At the age of 19 she was diagnosed as having CF after a positive sweat test. Subsequently, her symptoms improved on regular steroid therapy.

JC had recurrent chest infections and an equivocal sweat test. When CF was diagnosed on the basis of P67L/G542X compound heterozygosity, it was pointed out that his younger brother (but not his older brother) had identical symptoms. His younger brother is a P67L heterozygote, his older brother a G542X heterozygote.

KB had a history of chest infections but a normal sweat test at the age of 12 . At 16 the presence of significant respiratory disease and nasal polyps led to reinvestigation of the diagnosis by molecular methods.

BH and SH are sibs. SH had an abnormal sweat test at the age of 3, but thereafter doubts arose about the diagnosis of CF. She has a complex chromosomal rearrangement involving chromosomes 1,13 , and 16 and moderately severe learning difficulties. Her older brother, $\mathrm{BH}$, is perfectly normal in all respects except for a tendency to asthma.

Table 2 Sweat test data on P67L patients

\begin{tabular}{lllll}
\hline Patient & Age when tested & Sodium (mmoll) & Chloride (mmolll) & Interpretation* \\
\hline DO & Never & & & \\
EM & 14 & & 62 & Equivocal \\
& 14 & & 50 & Equivocal \\
AL & Never & 86 & 77 & \\
AM & 26 & 70 & 63 & Abnormal \\
& 26 & 67 & 60 & Equivocal \\
& 26 & 85 & 67 & Equivocal \\
ED & 33 & 81 & 58 & Equivocal \\
& 33 & Records lost & & Equivocal \\
JM & $?$ & 97 & 69 & Abnormal \\
MA & 19 & Screening chloride electrode & & Equivocal \\
LB & 19 & 53 & 55 & Abnormal \\
JC & 8 & 50 & 56 & Equivocal \\
& 14 & 43 & 54 & Equivocal \\
& 14 & 49 & 37 & Equivocal \\
KB & 12 & 67 & 63 & Normal \\
& 15 & 99 & 80 & Equivocal \\
BH & 8 & 49 & 38 & Abnormal \\
& 14 & 82 & 75 & Normal \\
SH & 3 & 61 & 61 & Abnormal \\
& 3 & 60 & 46 & Equivocal \\
& 6 & 72 & 65 & Normal \\
& 11 & 83 & 87 & Equivocal \\
AT & 1 & 56 & 58 & Abnormal \\
& 1 & 53 & 54 & Equivocal \\
& 1 & & & Equivocal \\
\hline
\end{tabular}

^Conclusion reported by testing laboratory
AT was the product of IVF from a P67L sperm donor. She had a collapsed right upper lobe at presentation aged 1 year. Her first sweat test was abnormal and the next two equivocal. Her early diagnosis was the result of P67L screening being introduced for cases where a diagnosis of CF was possible.

METHODS

DNA analyses

Samples referred from patients where there was a possible diagnosis of CF were tested for the presence of up to 26 mutant alleles: $\triangle F 508$, G551D, G542X, R117H, $\Delta \mathrm{I} 507, \mathrm{~V} 520 \mathrm{~F}$ R553X, 621+1G-T, A455E, N1303K, R560T, ${ }^{8} \mathrm{Q} 493 \mathrm{X},{ }^{8} \mathrm{C} 524 \mathrm{X},{ }^{9} \mathrm{Q} 1291 \mathrm{H},{ }^{9} \mathrm{G} 85 \mathrm{E},{ }^{10}$ 1717-1G-A, ${ }^{11} \mathrm{D} 110 \mathrm{H},{ }^{12} \mathrm{G} 458 \mathrm{~V},{ }^{13} \mathrm{~W} 1282 \mathrm{X},{ }^{14}$ R1283M, ${ }^{15} \quad 4005+1 G-A,{ }^{16} \quad$ G1244E, ${ }^{17}$ D1270N, ${ }^{18} \mathrm{~S} 1255 \mathrm{X},{ }^{19} 1898+1 \mathrm{G}-\mathrm{A},{ }^{20}$ and P67L. ${ }^{6}$ The first 10 of the above were tested in a single tube multiplex system $^{7}$ and the remainder by the referenced methods. ${ }^{8-20}$ The three locus IVS8CA-IVS17bTA-IVS17bCA haplotype was scored by the method of Hughes et al. ${ }^{21}$

\section{Sweat testing}

For six of the patients (AM, MA, KB, BH, $\mathrm{SH}$, AT) sweat testing was carried out in Edinburgh as described previously. ${ }^{22}$ In two cases (DO, AL) sweat tests were never performed since there has not been a clinical indication. The remaining five cases were tested in other centres.

\section{Pancreatic status}

Pancreatic status of the three youngest patients was established by stool trypsin measurement. ${ }^{23}$ In the other cases, assessment was made on the basis of a normal growth pattern, normal stools, and absence of response to pancreatic enzymes.

\section{Results}

Diagnostic characteristics of the 13 P67L patients are shown in table 1 . Most were compound heterozygotes for $\Delta F 508$. Ten of the 13 were pancreatic sufficient. If patient AT is ignored (because she was detected after the introduction of P67L screening for "possible" CF cases), the median age of the other 12 is 28.5 years and the median age of diagnosis 23 years. However, this includes scoring JM's 
Table 3 Comparison of four dominant mild alleles

\begin{tabular}{lllllll}
\hline Allele & No of patients & Age, $y(S D)$ & $\begin{array}{l}\text { Age at diagnosis, } y \\
(S D)\end{array}$ & PS \% & \multicolumn{2}{l}{$\begin{array}{l}\text { Sweat chloride, mmolll } \\
\text { (SD) }\end{array}$} \\
\hline R117H & 23 & $23.5(9.6)$ & $10.2(10.5)$ & 87 & $80(18)$ & Ref \\
A455E & 33 & 23 & $15.0(10.6)$ & 79 & NG $^{\star}$ & 2 \\
$3849+10 \mathrm{~kb}$ & 15 & $20.5(9.9)$ & $12.5(8.8)$ & 67 & $62(17)$ & 4 \\
P67L & 13 & $24.6(11.1)$ & $22.5(11.3)$ & 77 & $57(9)$ & 4 \\
\hline
\end{tabular}

^NG, not given

diagnosis as having occurred at the age of 19 on the basis of a now lost positive sweat test. The average age and the average age of diagnosis of the whole set of 13 was 24.6 (SD 11.1) and 22.5 (SD1 1.3) years, respectively.

Sweat test data are shown in table 2. Six of the cases were tested at the Royal Hospital for Sick Children, Edinburgh, which cites a normal sweat chloride for any age as $<50$ $\mathrm{mmol} / \mathrm{l}$ and between 50 and 70 as "equivocal". ${ }^{22}$ Owing to increasing values with advancing age, sweat sodium measurement is less definitive and some normal adults may have values $>70 \mathrm{mmol} / \mathrm{l}^{22}$ In table 2 , "interpretation" means the conclusion reported by the laboratory carrying out the testing. The two infertility patients have never been tested. In all other cases the data were regarded as too equivocal to support a diagnosis of CF. Taking only the most recent determination for each patient, the average sweat chloride concentration was $57 \pm 9 \mathrm{mmol} / \mathrm{l}(\mathrm{n}=9)$ and the average sweat sodium $66.1 \pm 17.8 \mathrm{mmol} / \mathrm{l}$ $(n=8)$.

In four of the 13 cases the intragenic IVS8CA-IVS17bTA-IVS17bCA haplotype associated with the P67L mutation was 16-7-17, as previously found. ${ }^{21}$ In one case (LB) the patient was homozygous for this haplotype and in another three (JC, $\mathrm{BH}, \mathrm{SH}$ ) parents were available for direct testing. In the remaining nine cases the 16-7-17 haplotype could be inferred to be associated with P67L.

If the two cases where the first presentation was infertility are ignored, P67L was found on 10 independent CF chromosomes of 730 scored $(1.4 \%)$.

\section{Discussion}

The P67L allele was first reported by Hamosh et $a l^{t}$ as a mutation found in a pancreatic sufficient patient. However, only two further cases have been subsequently reported, both without clinical data. ${ }^{21}$ We were therefore surprised at its relatively high frequency. Our estimate of $1.4 \%$ of CF chromosomes makes it the sixth most common mutation (after $\Delta \mathrm{F} 508, \mathrm{G} 551 \mathrm{D}$, G542X, R1 17H, and 1717-1G-A) in Scotland. Almost certainly, given the atypical nature of most presentations, this is a considerable underestimate. For example, we find another mild allele, $\mathrm{R} 117 \mathrm{H}$, occurring on $2.4 \%$ of $\mathrm{CF}$ chromosomes from homozygotes and on $6.9 \%$ of CF chromosomes from unselected heterozygotes. It is interesting that all 13 P67L mutations were on the same genetic background, 16-7-17, which occurs on only about $11 \%$ of normal chromosomes. ${ }^{21}$

For many of the cases, with the exception of the two male infertility patients, there was some suspicion of $\mathrm{CF}$ at earlier ages. However, the diagnosis could not be confirmed by sweat test for, as table 2 shows, none of the patients had consistent chloride values in the pathological range. Furthermore, only three of the 13 were pancreatic insufficient. This, together with the variability in presenting symptoms, means that it is no surprise that the median age of diagnosis was 19 years (average 22.5), against a 1984 to 1990 median age of diagnosis of children with CF in the Edinburgh area of 5 months. ${ }^{22}$

Our claim that P67L confers a "dominant mild" phenotype rests on mild disease being found in patients who were compound heterozygotes for other known severe alleles $(\Delta \mathrm{F} 508$, G542X, and 1717-1G-A). A possible exception to this are the sibs $\mathrm{BH}$ and $\mathrm{SH}$ who had Q1291H on the other allele. To our knowledge this allele has only been found in three cystic fibrosis patients, the two here (one of whom was also the subject of the first Q1291H report $^{9}$ ) and one other. The third case, also originating in Scotland, was from a child who died in hospital aged 3 years, having been an emergency admission with a 10 day history of upper respiratory tract infection. Although the other CF allele is not known in this case, the existence of such severity argues against Q1291H conferring the dominant mild effect in $\mathrm{P} 67 \mathrm{~L} / \mathrm{Q} 1291 \mathrm{H}$ compound heterozygotes.

In a recent survey by Kerem and Kerem, ${ }^{1}$ only three CF alleles, R117H, A455E, and $3849+10 \mathrm{~kb} \mathrm{C}-\mathrm{T}$, were regarded as unequivocally conferring a dominant mild effect. Two others, G85E and R334W, were seen as "substantially variable". Table 3 compares the characteristics of P67L with the three accepted as being mild. In terms of age, age at diagnosis, probability of pancreatic sufficiency, and normality of sweat chloride levels, P67L compound heterozygotes are probably the least seriously affected of any CF case where the molecular pathology has been established.

This work was supported by a grant from the Cystic Fibrosis Trust.

1 Kerem B, Kerem T. The molecular basis for disease variability in cystic fibrosis. Eur ₹ Hum Genet 1996;4:65-73.

2 The Cystic Fibrosis Genotype-Phenotype Consortium Correlation between genotype and phenotype in patients Correlation between genotype and phenotype in patien
with cystic fibrosis. NEngl f Med 1993;329:308-13.

$3 \mathrm{Gan} \mathrm{KH}$, Veeze HJ, van den Ouweland AMW, et al. A cystic fibrosis mutation associated with mild lung disease. $N$ Engl f Med 1995;333:95-9.

4 Augerten A, Kerem B, Yahav Y, et al. Mild cystic fibrosis and normal or borderline sweat test in patients with the $3849+$ $10 \mathrm{~kb}$ C-T mutation. Lancet 1993;342:25-6.

5 Highsmith WE, Burch LH, Zhou Z, et al. A novel mutation in the cystic fibrosis gene in patients with pulmonary disease but normal sweat chloride concentrations. $N$ Engl $f$ Med 1994;331:974-80.

6 Hamosh A, Macek M, Kiesewetter S, et al. Cystic Fibrosis Genetic Analysis Consortium Newsletter No 54.

7 Axton R, Brock DJH. A single-tube multiplex system for the simultaneous detection of 10 common cystic fibrosis mutations. Hum Mutat 1995;5:260-2.

8 Kerem B, Zielenski J, Markiewicz D, et al. Identification of mutations in regions corresponding to the 2 putative 
nucleotide (ATP)-binding folds of the cystic fibrosis gene. Proc Natl Acad Sci USA 1990;87:8447-51.

9 Jones C, McIntosh I, Keston M, et al. Three novel mutations in the cystic fibrosis gene detected by chemical cleavage: analysis of variant splicing and a nonsense mutation. Hum Mol Genet 1992;1:11-17.

10 Zielenski J, Bozon D, Kerem B, et al. Identification of mutations in exons 1 through 8 of the cystic fibrosis transmemtions in exons 1 through 8 of the cystic fibrosis transmem-
brane conductance regulator (CFTR) gene. Genomics brane conductance

11 Cremosi L, Seia M, Magnani C, Ferrari M. Rapid detection of $1717-1 \mathrm{G}-\mathrm{A}$ in CFTR gene by site-directed mutagenesis. Clin Chem 1991;37:1447-8.

12 Dean $M$, White MB, Gerrard B, et al. A 22 basepair deletion in the coding region of the cystic fibrosis gene. Genomics 1992;13:235-6.

13 Cuppens H, Marynen P, De Boeck C, et al. A child homozygous for a stop codon in exon 11 shows milder symptoms than her heterozygous nephew. 7 Med Genet 1990;27:717-19.

14 Vidaud M, Fanen $\mathrm{P}$, Martin J, et al. Three mutations in the CFTR gene in French cystic fibrosis patients: identification by denaturing gradient gel electrophoresis. Hum Genet 1990;85:446-9.

15 Cheadle JP, Meredith AL, Al-Jader LN. A new missense mutation (R1283M) in exon 20 of the cystic fibrosis transmutation (R1283M) in exon 20 of the cystic fibrosis trans1992;1:123-5.
16 Ferec C, Audrezet MP, Mercier B, et al. Detection of over $98 \%$ of cystic fibrosis mutations in a celtic population. Nat Genet 1992;1:188-91.

17 Devoto $M$, Ronchetto $P$, Fanen $P$, et al. Screening for non- $\triangle$ F508 mutations in 5 exons of the CFTR gene in Italy. Am $\mathcal{F}$ Hum Genet 1991;48:1127-32.

18 Anguiano A, Oates RD, Amos JA, et al. Congenital bilateral absence of the vas deferens - a primarily genital form of cystic fibrosis. $\mathscr{F A M A} 1992 ; 267: 1794-7$.

19 Cutting GR, Kasch LM, Rosenstein BJ, et al. Two patients with cystic fibrosis, nonsense mutations in each cystic fibrosis gene, and mild pulmonary disease. $N$ Engl 7 Med 1990;323:1685-9.

20 Strong TV, Smit LS, Nasr S, et al. Characterisation of an intron 12 splice donor in the cystic fibrosis transmembrane conductance regulator (CFTR) gene. Hum Mutat 1992;1: conductan

21 Hughes D, Wallace A, Taylor J, et al. Fluorescent multiplex microsatellites used to define haplotypes associated with 75 CFTR mutations from the UK on 437 CF chromosomes. Hum Mutat 1996;8:229-35.

22 Kirk JM, Keston M, McIntosh I, Al Essa S. Variation of sweat sodium and chloride with age in cystic fibrosis and normal populations: further investigations in equivocal cases. Ann Clin Biochem 1992;29:145-52.

23 Crossley JR, Berryman CC, Elliott RB. Cystic fibrosis screening in the newborn. Lancet 1977;ii:1093-5. 